\title{
Gold Brazing on the Concorde Airframe Hydraulic System
}

\author{
J. D. Rosser \\ British Aircraft Corporation, Bristol, England
}

As part of the over-all philosophy to achieve ninimum weight in keeping with cost considerations the Concorde aircraft built for airline service are fitted with hydraulic systems utilising, in the main, brazed assemblies of titanium alloy seamless drawn tube and machined fittings. These materials are used instead of the various grades of stainless steel that are used on the hydraulic systems of current generation civil aircraft. The lower density of the titanium alloys leads to a lower total weight, particularly as the strengths of the titanium alloys and the stainless steel materials are of the same order in the operating temperature range encountered in service. Stainless steel materials have not been eliminated entirely, however, and their use in specific applications is described here.

The use of a $4000 \mathrm{lbf} / \mathrm{sq}$ in operating pressure in the Concorde hydraulic system, in comparison with the 2,800 to $3,200 \mathrm{lbf} / \mathrm{sq}$ in used in the present generation of civil aircraft, also allows a considerable reduction in the working section size, and hence in the mass of the hydraulically operated mechanisms. To meet the safety requirements imposed by airworthiness authorities in respect of all civil aircraft, a triplicate hydraulic system is fitted to Concorde. As a consequence, weight saving on any particular item has up to a three-fold effectiveness.

In Concorde, the titanium alloy and stainless steel tubes range in size from $3 / 16$ inch O.D. $\times 0.018$ inch wall thickness to $11 / 4$ inch O.D. $\times 0.028$ inch wall thickness, with intermediate sizes of tube with wall thicknesses up to 0.064 inch, depending on service conditions. Typically, brazed assemblies contain between two and eleven brazed joints, each joint being brazed individually by induction heating techniques in a glass shroud containing inert gas (argon). The brazing alloys used are specific to the material combination and to the maximum temperature to which the assemblies may be subjected in service. The titanium alloys assemblies are brazed with a Ti-Ni-Cu laminated shim material, 0.002 inch thick, placed as a coil external to the joint. For stainless steel assemblies, two methods are used. First, assemblies subjected to moderate temperature conditions in service, are brazed with rings of a 70 silver-30 copper alloy containing lithium, placed externally to the joint; secondly, for regions of the aircraft which may be subjected to higher temperatures, the assemblies are brazed with shims of 82 gold-18 nickel alloy, 0.002 inch thick, inserted into the joint gap in a single thickness. It is not current practice to braze titanium alloy tube or fittings to stainless steel tubes or fittings.

Because of the high operating pressures and consequent stress levels in the tube while in service, high levels of integrity are required consistently in every brazed joint, with minimum requirements of 90 per cent joint filling, smooth uniform brazed fillets, and voids when present not to exceed 25 per cent of the joint overlap length. The use of brazing fluxes is not acceptable for these applications because of the difficulty of ensuring that all traces of flux have definitely been removed and to avoid possible contamination of the hydraulic fluid. Additionally, the titanium alloys are extremely reactive with fluxes and with air at brazing temperatures, and for the above reasons all brazing is carried out with argon purging, both to the inside and outside of the assembly to be brazed. Heating of the assembly to be brazed is achieved by induction techniques which incorporate automatic controls to ensure repeatability of the machine parameters. These parameters are established and scheduled for each joint configuration on representative component pieces which are subjected to detailed non-destructive testing and metallurgical examination prior to the issue of a process schedule. To ensure the standard of brazing is maintained and that the brazed joints conform with the mandatory requirements, every brazed assembly is subjected to pressure testing and radiographic examination.

As the brazed joints are required to be made without prefluxing or flux, grades of brazing alloy are required which exhibit good wetting characteristics, and to assist this and to achieve uniform capillary flow, joint tolerances and clearances are specified for each joint material combination, together with the relevant braze alloy. The clearances at room temperature are of considerable importance when different materials are used for the various parts of the assembly, particularly if, in addition to different thermal expansion characteristics, one of the materials undergoes a structural transformation below the brazing temperature range. While the braze alloy 


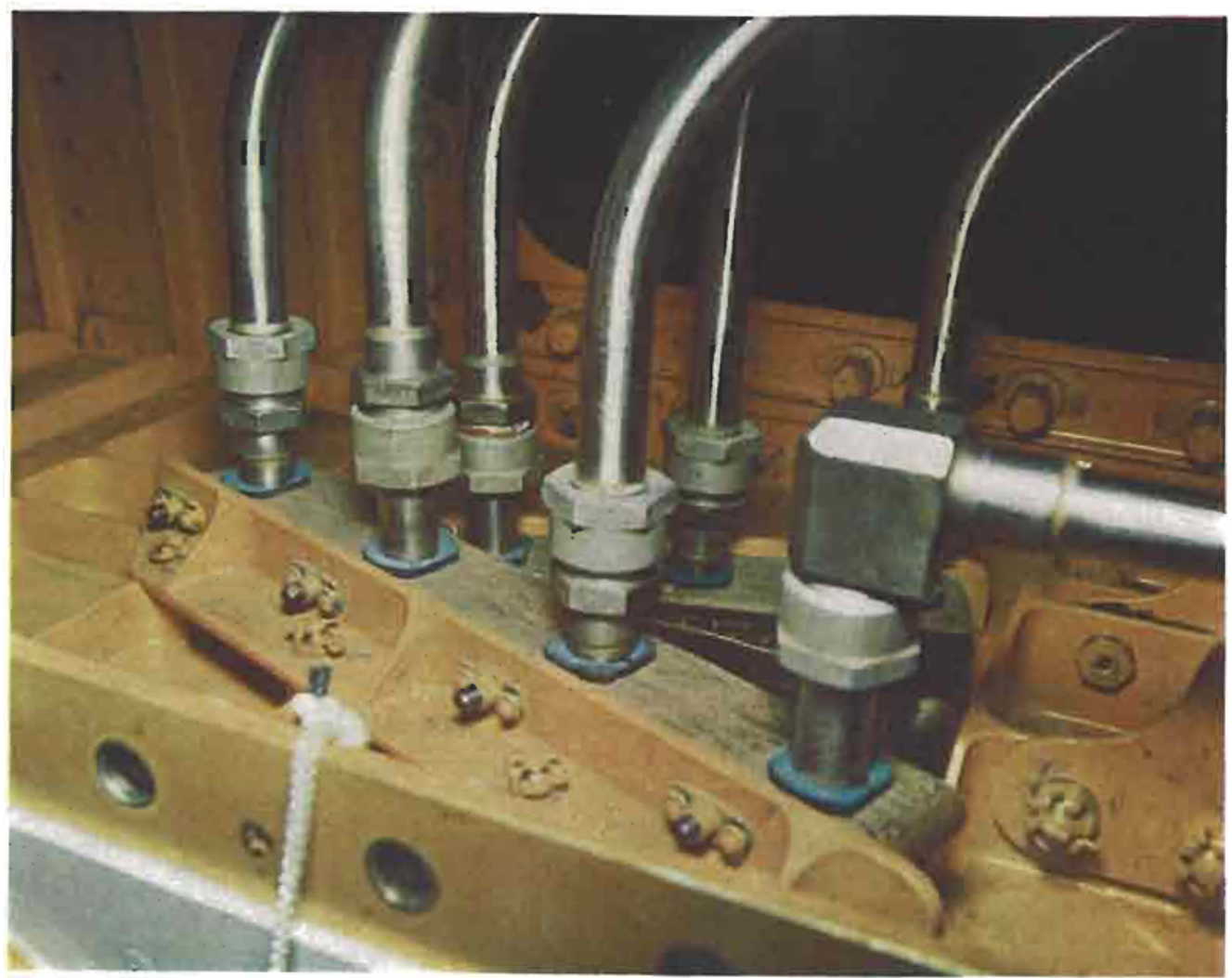

The hydraulic system in Concorde controls the yariable geometry air intake, the normal aerodynamic eontrol surfaces, the operation of the undercarriage and of the droop nose and visor. The complex of hydraulic lines comprises both titanium alloy and stainless steel tuling; where these might be exposed to high temperatures stainless stcel tubes and fittings are agsembled with an 82 per eent gold-18 per cent nickel brazing alloy. This part of the system controls the variable air intake

is required to possess good wetting characteristics, it is imperative that the molten braze alloy does not cause preferential dissolution of the parent material grain boundary regions, excessive general dissolution of the parent material or the formation of undesirable intermetallic compounds.

All the materials (tube, fittings and brazing alloys) are inherently resistant to corrosion, and under normal good housekeeping conditions exhibit only slight surface discolouration, grease or contamination from handling and processing. However, as flux is not used, careful cleaning using ultrasonic plus solvent techniques to remove these surface contaminants is essential. This is carried out immediately prior to assembly and brazing, as it has been established that contamination within the joint is the primary cause of poor quality joints.

Because of the small clearances defined for certain material combinations and the necessity for careful pre-cleaning, the brazing alloy is placed as an external ring at the junction of the tube to the machined socket and this requires the braze alloy to exhibit good fluidity once melting has started.

While most of the hydraulic system is fabricated from titanium alloys, limitations on the use of this material are incurred because of its poorer forming characteristics. Extensive testing under fatigue conditions at the marginally elevated temperature to which Concorde generally is subjected in service, has shown that the titanium alloy exhibits decreasing fatigue performance when the tube is formed to bend radii below about five times the outside diameter of the tube. This effect is made worse by the development of ovality of the tube at the bend, this mode of deformation being a normal characteristic for all materials unless well-established procedures are followed. The more amenable forming characteristics of the stainless steel tube materials allows forming down to a radius of about three times the outside diameter of the tube, while maintaining both acceptable ovality and fatigue performance. Thus it is necessary, in a few regions where insufficient space exists to accommodate the titanium alloy tubes with the larger bend radii, for stainless steel materials to be used in the marginally elevated temperature regions.

While under the above operating conditions the strength properties of the titanium alloys and stainless steels are similar, the titanium alloys and the associated brazed joints exhibit a greater loss of mechanical strength as the temperature increases. Hydraulic systems materials and components within 
To achieve the high level of integrity demanded in every braxed joint in Concorde, the stainless steel tubes and fittings are brazed individually with the gold nickel alloy in a glass sheath purged with argon. Heating is by an induction coil with automatic control. Every brazed jointand there are several hundreds of them in each Concordeis then submitted to pressure testing aud radiographic examination

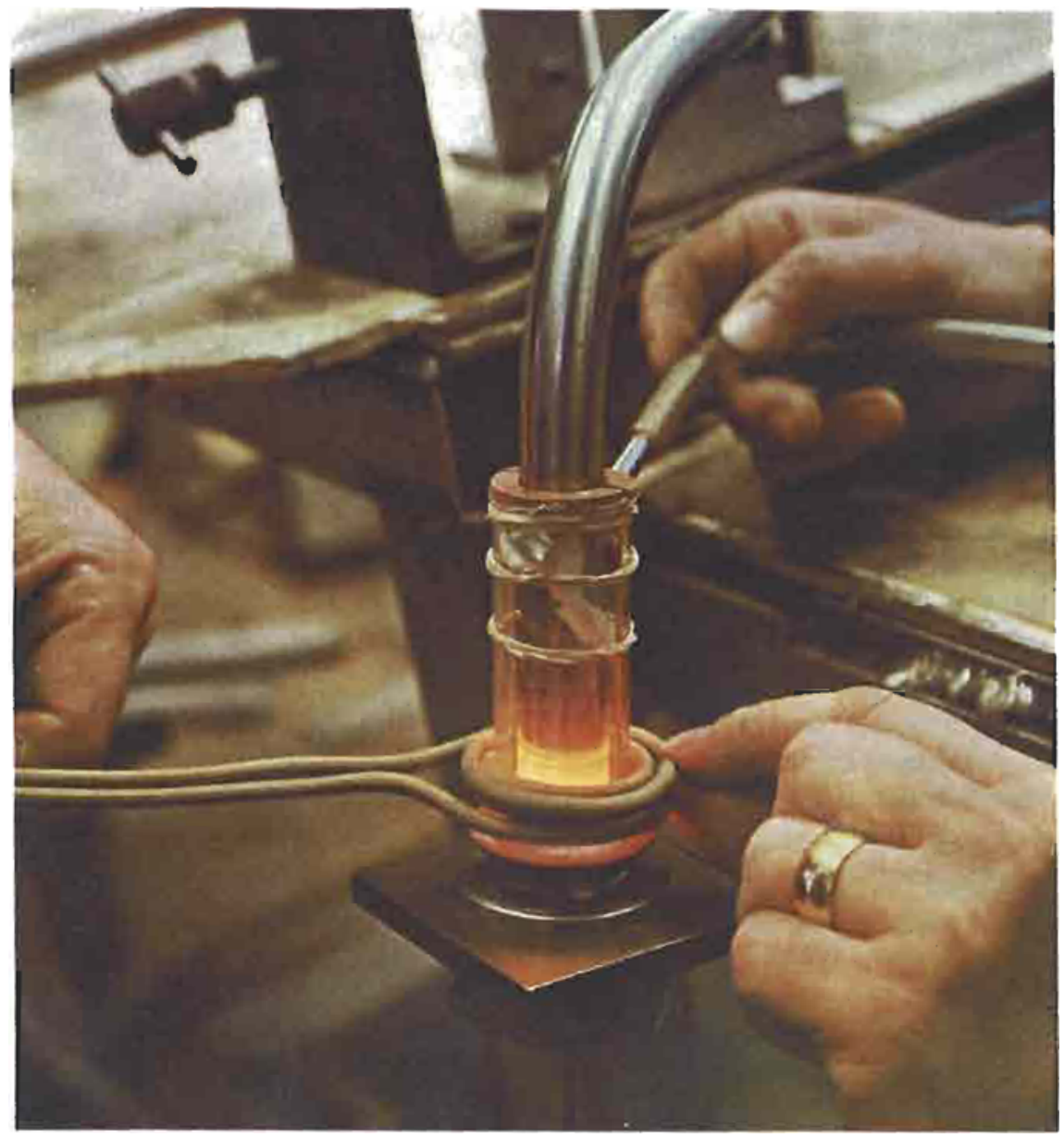

the engine bays, or its immediate environs, are required to withstand a "torching flame" test which simulates the conditions which can arise should perforation of an engine combustion chamber occur while the engine is delivering thrust, projecting a searing tongue of flame into the engine bay until engine shut down is achieved. Under such conditions, any hydraulic pipe or joint must withstand direct impingement of the flame, until engine shut down, without failure of the hydraulic system locally, otherwise secondary fire hazards are greatly increased by the high pressure dispersion of hydraulic fluids into the flame. Protection for indefinite exposure to flame impingement is not practicable, hence the optimum procedure is accepted to be achieving engine shut down as rapidly as possible. "Torching flame" tests are carried out on typical assemblies which include both mechanical and brazed joints, pressurised to the working pressure with the appropriate hydraulic fluid under "no flow" conditions (i.e. no benefit from cooling flow) to equate with the most severe conditions that can occur in service. Specimens subjected to "torching flame" test are required to maintain integrity for a limited duration, the test conditions being of such severity that all materials suitable for hydraulic systems applications are eventually degraded to an unacceptable extent.

Consideration of the elevated temperature properties of the titanium alloys indicated that these materials would not perform satisfactorily under this test. This was confirmed when tests were carried out, and unacceptable levels of joint relaxation in the mechanical joints, deterioration of the brazed joints and distortion of the tube material occurred.

In comparison, the performance of stainless steel assemblies was expected to meet the "torching flame" test requirement, other than inadequacies arising from the use of the lower melting-point braze alloy. On test, premature failure occurred because of remelting of the $70 \mathrm{Ag}-30 \mathrm{Cu}+\mathrm{Li}$ braze alloy and separation of the joint, confirming the unsuitability of this brazing alloy for this particular application. The indication was that substitution of a higher melting-point braze alloy should enable a satisfactory material/braze joint combination to be established.

Consideration of the various classes of brazing alloys available indicated that the gold-containing braze alloys offered a wide choice, which, with their higher melting temperatures, would enhance elevated 
temperature service performance. Additionally, these alloys exhibited other favourable features such as good corrosion resistance and oxidation resistance, together with maintenance of good ductility after brazing. The extensive use of various gold-bearing brazing alloys by aero-engine manufacturers indicated that these materials would exhibit satisfactory metallurgical characteristics both during brazing assembly operations and under extended service conditions. None of the available gold-bearing braze alloys have melting temperatures above the temperature of the "torching flame" and after consideration of the various possibilities the $82 \mathrm{Au}-18 \mathrm{Ni}$ eutectic alloy was selected for initial evaluation of both its brazing characteristics and its performance during the "torching flame" tests. While this alloy was not one of the alloys within the higher melting-point range, its melting point is about $170^{\circ} \mathrm{C}$ above that of the silver-copper alloy.

The brazing trials with the $82 \mathrm{Au}-18 \mathrm{Ni}$ brazing alloy and the $21 \mathrm{Cr}-6 \mathrm{Ni}-9 \mathrm{Mn}$ and $14 \mathrm{Cr}-5 \mathrm{Ni}$ stainless steels showed the materials to be completely compatible. Brazing at excessively high temperatures and for an extended time, showed general, smooth contoured, dissolution of the stainless steel parent materials with no evidence of intergranular penetration nor any evidence of the formation of intermetallic compounds.

Stainless steel specimens of identical configuration to those previously used for the "torching flame" test were then produced using the $82 \mathrm{Au}-18 \mathrm{Ni}$ braze alloy. When subjected to the "torching flame" test with full hydraulic pressure applied, these specimens survived the minimum design requirement time of direct flame impingement with no sign of distress. As a result of these tests, and the preceding metallurgical assessment, the use of stainless steel tube and machined fittings brazed with the $82 \mathrm{Au}-18 \mathrm{Ni}$ braze alloy has been established for use in the Concorde airframe hydraulic system in the engine bay region.

With the use of the $82 \mathrm{Au}-18 \mathrm{Ni}$ brazing alloy for these applications there have arisen two features which are of benefit in monitoring product quality during manufacture. The high density of the gold in the braze alloy clearly reveals the presence of the $82 \mathrm{Au}$ $18 \mathrm{Ni}$ alloy on radiographic examination, which assists in the interpretation aimed at confirming that the correct procedures have been followed, and highlights any lack of uniformity of the braze film. Dissolution of the parent materials enlarges the volume over which the gold content is distributed and provides a continuous monitor of the maintenance of procedures and correct functioning of the brazing equipment. Additionally, the differences in density between the titanium alloys and stainless steel materials (tubes and machined fittings) and the various brazing alloys provide a continuous monitor, during radiographic examination, on the correctness of the materials in the various assemblies.

By utilising these various materials and brazing alloys, relative to the specific applications existing in Concorde, an optimum weight-cost-design concept has been achieved. This, together with the direct confirmation that the correct procedures and materials have been used, engenders a high level of product quality and reliability.

\section{Ultrasonic Wire Bonding of Gold}

A three-year programme of work designed to improve the quality and reliability of ultrasonic welds between aluminium or gold interconnection wires and thickfilm circuit materials, sponsored by the British Ministry of Defence, has been completed at the Welding Institute. The full report, by K. I. Johnson, M. H. Scotr, and D. A. Edson, remains confidential to members of the Institute, but the broad conclusions arrived at are of considerable interest to the semiconductor industry.

To monitor the variables in ultrasonic bonding, a light cell-fibre optic system was attached to the welding machine to measure the small high-frequency vibrations. In use this device emphasised the problem of obtaining reproducible bonding conditions on a number of welding machines and showed the value of calibrating their output with this or some similar monitor.

Wedge bonding of aluminium wires to three thickfilm materials-palladium-silver, palladium-gold and gold-was more difficult and critical than to aluminium thin films, and the palladium-gold was more trouble- some than the others, possibly due to differences in hardness. Wedge weld strengths were dominated by the thinned section at the edge of the weld-a factor possibly sensitive to tool profile-whereas in ball or nail-head jointing the wire is welded where it is locally enlarged by the balling.

In the case of ball bonding, conditions were naturally found to be much more tolerant for the three thick-film materials tested, although higher energies were needed for the alloy layers.

Unfortunately, of course, ball bonding is possible only at one end of the lead wire, the other being joined by a type of wedge bonding. Although in the examples given this latter process applied a much greater deformation than for the aluminium wedge bonding, a much greater tolerance was obtained with gold, especially when vibrating along the wire axis. None the less, the gold wedge bonds can be found to be suspect even under optimum conditions. But over-all the report clearly brings out the greater flexibility, tolerance and consistency of the nail-head bonding of gold.
G. I. D. 